\title{
CFD Modelling and Real-time testing of the Wave Surface Glider (WSG) Robot
}

\author{
Mohammad Reza Salari and Amir M. Anvar \\ The University of Adelaide \\ School of Mechanical Engineering \\ Adelaide, Australia \\ Emails: mrezasalari@gmail.com; amir.m.anvar@gmail.com
}

\begin{abstract}
This paper consists of two main parts. First part describes a new method for investigating the dynamic behaviour of a Wave Surface Glider (WSG) robot with the help of CFD analysis.

The second part focuses on the real-time testing of this platform and comparing the results obtained from the trial. WSG test-bed, designed and manufactured by the University of Adelaide, is categorised as a new marine vehicle which is fully dependant on sustainable energy of ocean waves and the sun.

Abundant energy of ocean waves is converted to propulsion, which allows this vehicle to roam freely in the ocean and gather useful oceanic data. Solar panels installed on the vehicle's surface, supplies the electricity for electronic components of this vehicle such as sensors (e.g. temperature sensor, servo, GPS, compass and etc.).

This paper discusses the computational fluid analysis approach that is employed to extract the contributing propulsive forces generated by the robot and relate this force to characteristics of regular waves and sea states in the ocean. Then, the robot has been taken for a real-time test and the results have been reported.
\end{abstract}

Keywords: Wave Surface Glider, robot, marine vehicle, dynamic model, fluid dynamic analysis 


\section{INTRODUCTION}

Wave Surface Glider (WSG) robot test-bed, built by the University of Adelaide, has a newly introduced concept which is capable of satisfying numerous marine applications. It has the capability of patrolling in a predefined ocean area as well as following waypoints in the ocean in order to gather useful data such as ocean's salinity, temperature, climate and etc [1].

This marine vehicle consists of two main parts; a floating part which is located on the surface of the ocean (the float) and the submerged part (the glider) which is gliding approximately seven meters below the surface of the ocean. These parts are connected via (umbilical) a tether cable which is mainly responsible to transfer the forward motion of the glider to the float. Since the float elevates with the waves in the ocean, it pulls the glider up. Lift force generated by the float will be converted into forward thrust because of the aerofoil shaped fins located on the glider and pushes the float and the whole body together. The unique architecture of this robot allows it to roam freely in the ocean while consuming wave and solar energy only [2]. Figure 1 shows the WSG robot.

Another unique feature of this robot is to be utilized as a floating platform for landing quadrocopters and recharging their batteries. This can help the quadrocopters to map a region of ocean-air surrounding the platform while using the platform as a station on the ocean to recharge their power supply.

Analysis of dynamic behaviour of this robot in real-time is considered to be the most important factor contributing to the accomplishment of the assigned missions. In order to deliver the desired outcome from this vehicle in a marine application, this vehicle has to overcome the harsh conditions of the ocean. This leads to the demand of a reliable anticipation of the behaviour of this robot in real-time condition.

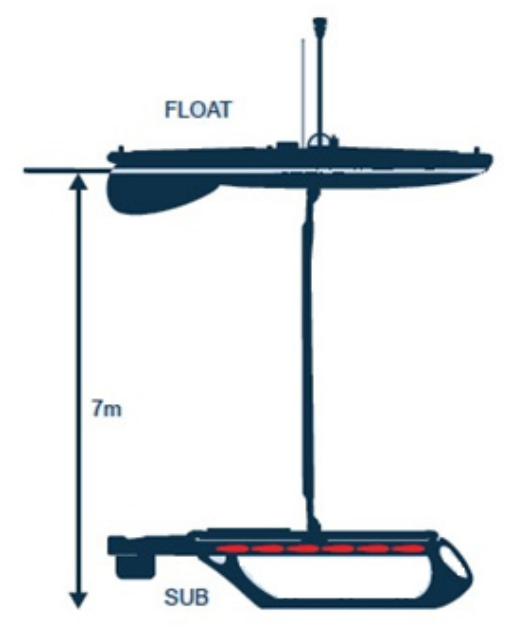

Figure 1. Wave Surface Glider robot[3]

In this paper, a method will be introduced to describe dynamic behaviour of this robot by linking the propulsion system of this robot to the environmental factor of the ocean. Then by defining appropriate assumptions, final CFD model will be introduced and the results will be discuss accordingly. Also, the results obtained from the real-time testing of the robot have been reported and suggested modifications have been discussed.

\section{BACKGROUND AND RELATED WORKS}

Analysis of the dynamic behaviour of marine vehicles has been done by numerous scientists. For a marine vehicle similar to the WSG robot, there are only a few papers describing the dynamic modelling of such systems. Kraus and Bingham [4] proposed an estimation algorithm and an extended Kalman filter, using two body dynamics to describe the potential of the Wave Glider for precise localization. The focus of the mentioned work was on the relative motions of the float and glider.

Nicholas D. Kraus [5] published their work considering six-degree-of-freedom in the dynamics equations of motion of the Wave Glider. The work was consistent with the common method of dynamic modeling of marine vehicles which can be found in numerous marine literatures. The focus of the work was to analyze the kinetics of the Wave Glider with respect to three different coordinate systems located on each part independently, then transfer all parameters to the main coordinate frame located on the tethered (umbilical) between the float and the glider and describe the motion with respect to that origin. The main issue with that work was the inconsistent results from simulation results compared to the real time data. Lack of enough hydrodynamic parameters especially for the submerged part and also complicated propulsion system of this vehicle could be mentioned as one of the valid reasons for such inconsistency.

In this paper, two parts of the WSG robot are considered separately. The glider which plays the role of the propulsion system of the vehicle is simplified and it is replaced with its effective forces only. The float is considered as an object sailing through the ocean which uses the power supplied by the glider's propulsive force. 


\section{THE GLIDER EFFECTIVE FORCES, SIMPLIFICATION, ASSUMPTIONS AND THEORIES}

The submerged part of the WSG robot is mainly responsible for providing thrust for the vehicle and keeping it on a predefined course. This force is produced in only one direction. The main parts of the Glider as it is shown in Figure 2 represent the WSG's propulsion system which is motivated with propulsion force, via the fins. These fins are designed to move the robot by converting the lift force of the glider into thrust.

Considering only the wings of the glider and applying fluid dynamic analysis on them, the thrust forces have been obtained. This work has been done with the help of a Computational Fluid Dynamic (CFD) software package such as ANSYS. In this work, these forces have been considered as the propulsive forces of the vehicle.

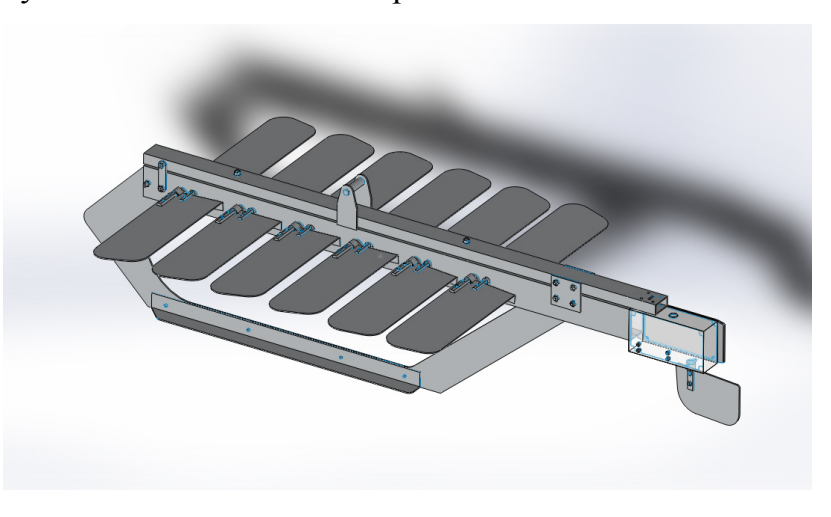

Figure 2. Propolsion System of the WSG robot (the glider) (modelled by SOLIDWORKS)

It is necessary to make the model as simplified as it is possible for the purpose of fluid dynamic analysis. These simplifications resulted in delivering the outputs of the software in shorter time. In addition, on some cases the results are more reliable. In this work, since the model is symmetric and all the fins have equal dimensions, the analysis can be done for one fin only and then repeated for other fins.

For fluid dynamic analysis as well as dynamic modeling of the WSG robot, it is necessary to consider the condition of the elevation of the vehicle in the ocean. For that matter, characteristics of sea state 3 is considered. In addition, it is necessary to make appropriate assumptions. These assumptions are listed as follows.

- The glider is negative buoyant proportional regarding to its volume. This means that the force caused by weight of the glider has higher value than its buoyancy.

- The fins are the only components which supply the glider with a thrust force.

- The glider always falls at higher acceleration than the float. In other words, the tethered umbilical is always in tension.

- The ocean waves assumed to follow the exact ideal pattern (regular wave) which is presented by numerous marine literatures[6].

- Constant values for the fluid analysis are considered for chosen sea states characteristics based on data obtained from Bales [7].

- Heading angles are assumed to be the same for the float and the glider.

\section{REGULAR WAVE THEORY AND SEA STATE CHARACTERISTICS}

Regular wave theory describes ocean waves as sinusoidal waves. Regular wave mathematic is presented in Equation 1[6].

$$
\varsigma(x, t)=\varsigma_{a} \sin (\omega t-k x+\varepsilon)
$$

Where $\zeta(\mathrm{x}, \mathrm{t})$ is the wave elevation at time $t$ and position $x, \omega$ is the frequency of the wave, $\varepsilon$ is the phase difference and $k$ is the wave number which is defined by $2 \pi / \lambda$, in which $\lambda$ is the wavelength. Figure 3 illustrates a regular wave with described formula and its parameters.

In figure $3, H$ is defined as height of a regular wave. In practice, to work with a better accuracy, significant wave height is usually reported as $H_{1 / 3}$ which is the average of the heights of the largest one third of the waves.

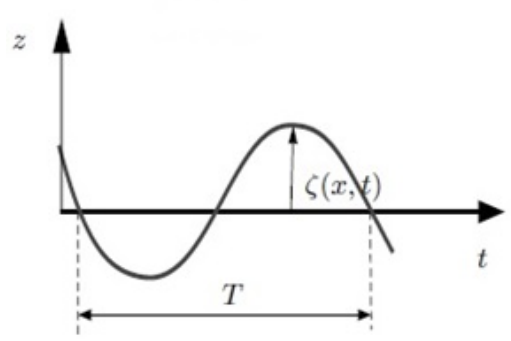

Figure 3. Regular wave parameters[6] 
Salari and Anvar, CFD Modelling and Real-time testing of the Wave Surface Glider (WSG) Robot

Characteristics of sea states 2,3,4,5 have been presented in table 1 .

Table 1. Characteristics OF SEA STATE $3[8,9]$

\begin{tabular}{|c|c|c|c|c|}
\hline \multirow{3}{*}{$\begin{array}{l}\text { Sea } \\
\text { State } \\
\text { code }\end{array}$} & \multicolumn{4}{|c|}{ Sea State Characteristics } \\
\hline & \multicolumn{2}{|c|}{$\begin{array}{c}\text { Significant wave height } \\
\mathrm{H}_{1 / 3}(\mathrm{~m})\end{array}$} & \multicolumn{2}{|c|}{ Wave Period (s) } \\
\hline & $\mathrm{H}_{1 / 3}$ Range & $\mathrm{H}_{1 / 3}$ Mean & Range & Average \\
\hline 2 & $0.1-0.5$ & 0.3 & $3.3-12.8$ & 7.5 \\
\hline 3 & $0.5-1.25$ & 0.88 & $5-14.8$ & 7.5 \\
\hline 4 & $1.25-2.5$ & 1.88 & $6.1-15.2$ & 8.8 \\
\hline 5 & $2.5-4$ & 3.25 & $8.3-15.5$ & 9.7 \\
\hline
\end{tabular}

It should be noted that these values have been considered as constant values for this work.

For CFD analysis of the glider, it is assumed that the glider is fixed and water falls on it. The vertical velocity of the fallen water is calculated with mathematical expressions of a regular wave which is presented in equation (2) on the surface of the water. [6].

$$
V_{y}=\omega \varsigma_{a} \cos (\omega t-k x)
$$

Where, $V_{y}$ represents the vertical velocity of the particles on the surface of water. Since the wave motion transfers from the Float on the surface to the underwater Propulsion System of the Glider, the velocity on the surface is considered for this case.

\section{METHODOLOGY FOR FLUID ANALYSIS}

The wings' angle of attack is dependent on the vehicle's position on the wave. When the vehicle is located on the highest point of a wave (crest), the angle of attack is considered to be zero and no force is generated. While the vehicle is moving to the lowest point of a wave (trough), the angle of attack begins to increase up to a maximum of 10 degrees relative to the glider's horizontal position. From the trough to the crest of the wave, a similar trend takes place only with a maximum of 20 degrees relative to the horizontal position. Table 2 illustrates the wings' angle of attack corresponding to the glider's position on regular waves.

Table 2. CORRESPONDING ANGLE OF ATTACK OF THE WINGS WITH RESPECT TO THE POSITION OF THE ROBOT ON THE WAVES

\begin{tabular}{|l|l|l|}
\hline $\begin{array}{l}\text { Fin's angle } \\
\text { of attack }\end{array}$ & $\begin{array}{l}\text { Glider's fins angle } \\
\text { of attack }\end{array}$ & $\begin{array}{l}\text { Vehicle's position on } \\
\text { a regular Wave }\end{array}$ \\
\hline $0^{\circ}$ & & \\
\hline $10^{\circ}$ & & \\
\hline $20^{\circ}$ & & \\
\hline
\end{tabular}




\section{RESULTS AND ANALYSIS}

CFD analysis has been done for one fin of the glider. The amount of force generated by this fin is considered to be the same for the rest of the fins. This allows for calculation of the summation of the forces generated by all the fins which result in the glider's propulsion force. Results from fluid analysis are presented in Table 3.

Table 3. RESULTS FROM ANSYS FOR MAXIMUM ANGLE OF ATTACK

As discussed in the previous section, as the vehicle moves through different position on a regular wave the fins change their angle of attack. The amount of force generated between these positions depends on the behaviour of a regular wave which is sinusoidal. Hence, the same behaviour for the generated force have been considered. Considering the characteristics of sea states 2, 3, 4 and 5 , the estimated pattern of the thrust force generated by the propulsion system of the WSG robot (the glider) have been plotted versus the wave period of a regular wave for corresponding sea states. Figure 4 represents the estimated pattern of the force generated by the glider in one cycle of a regular wave for sea states 2, 3, 4 and 5 .

It should be noted that the pattern only considers the regular wave theory (as assumed before) and also for sea state characteristics, the average statistical data was used. In other words, only average period and average wave height of a regular wave in different sea states have been considered. The pattern simply shows how much (approximately) force has been generated in a course of a wave. Furthermore, this figure has emphasized on the sensitivity of the WSG robot performance on the sea state in which the robot has been operating.

\begin{tabular}{|l|l|l|}
\hline \multirow{2}{*}{$\begin{array}{c}\text { Sea } \\
\text { state } \\
\text { code }\end{array}$} & \multicolumn{2}{|c|}{$\begin{array}{c}\text { Generated force with respect } \\
\text { to the corresponding wing's } \\
\text { angle of attack (N) }\end{array}$} \\
\cline { 2 - 3 } & $10^{\circ}$ & $20^{\circ}$ \\
\hline 2 & 1.28 & 2.44 \\
\hline 3 & 10.28 & 19.74 \\
\hline 4 & 33.62 & 64.74 \\
\hline 5 & 82.62 & 159.06 \\
\hline
\end{tabular}

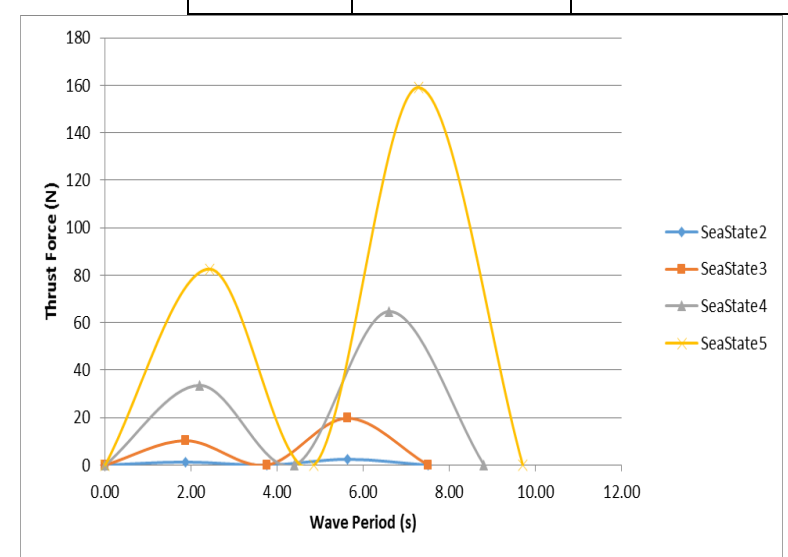

Figure 4. Pattern of the thrust forces generated by the glider in a complete period for sea states 2, 3, 4 and 5

\section{REAL-TIME TESTING OF THE ROBOT}

The real-time testing of the WSG robot has been explained. The main target of the experiment was focused on examining the functionality of the mechanical and the electronics of the system. In addition, a predetermined scenario has been designed and implemented in the navigational system of WSG robot.

\section{LOCATION AND SCENARIO}

The trial has been done in gulf St. Vincent, South Australia. The starting point located at 15 kilometers off the coast of Glenelg, South Australia. The reason for choosing this location for undertaking this experiment was the suitable depth of water (approximately $22 \mathrm{~m}$ ).

A waypoint scenario has been defined for the WSG robot for testing it in real-time. Start point has been selected prior to the experiment and programmed into the navigation system of the WSG robot. Figure5 shows the scenario for the real-time trial of the WSG robot.

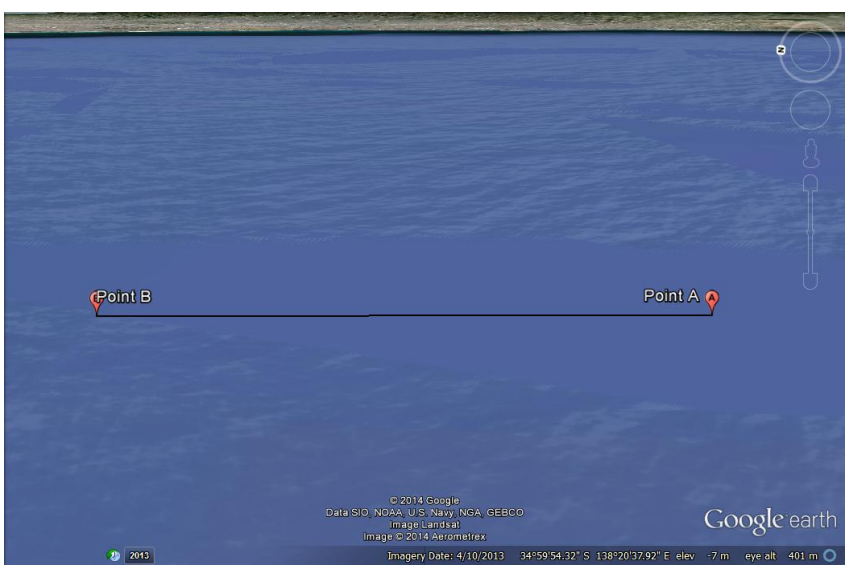

Figure 5. Scenario of trial 


\section{DEPLOYMENT}

Deployment of the WSG robot has been done by crew members of Ngerin research vessel and has been accomplished in two stages. First stage has involved placing the float on the surface of the water before placing the other components on the water. In the second stage the glider has been placed on the water and the umbilical cord has been released.

\section{RESULTS}

From the start point of the experiment toward the end point, the WSG robot has travelled for one hour and a half. In this period of time, WSG robot has travelled for 900 meters. Figure 6 has presented the coordination points recorded by the on-board GPS of WSG robot. According to this figure, the rudder controller of the WSG robot has been continuously attempting to correct the heading angle of the WSG robot. In other words, the rudder controller functionality has been considered as satisfactory.

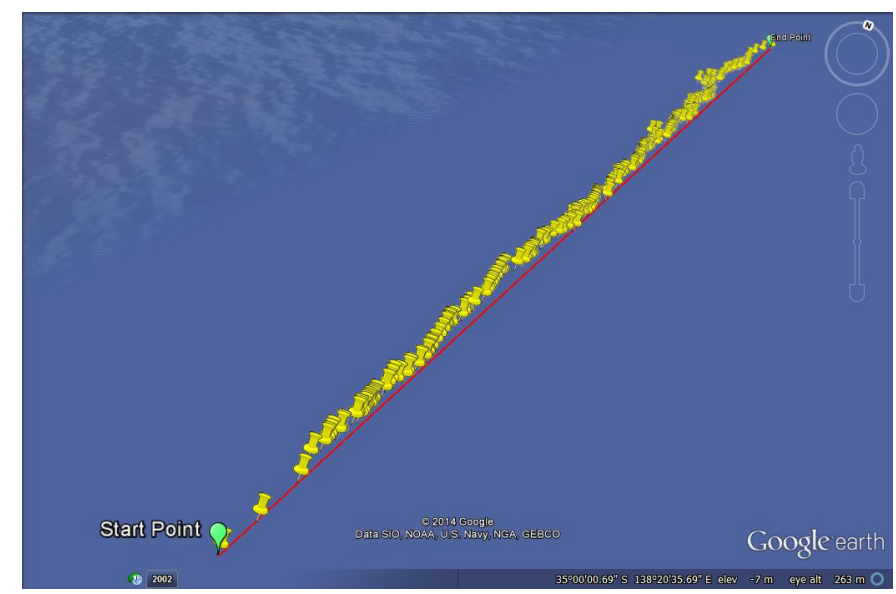

Figure 6. Recorded data for location from GPS

As it can be seen clearly from figure 7, the forward speed of the WSG robot has fluctuated during the trial. The presence of irregular waves has been responsible for the speed fluctuations. The forward speed of the WSG robot has reached a maximum value of $2 \mathrm{~m} / \mathrm{s}$ during the trial. Sea state at the time of the experiment was identified as sea state 2 and the wave height was recorded to be around 0.2 meter. The average speed of the WSG robot has been calculated to be about $0.17 \mathrm{~m} / \mathrm{s}$.

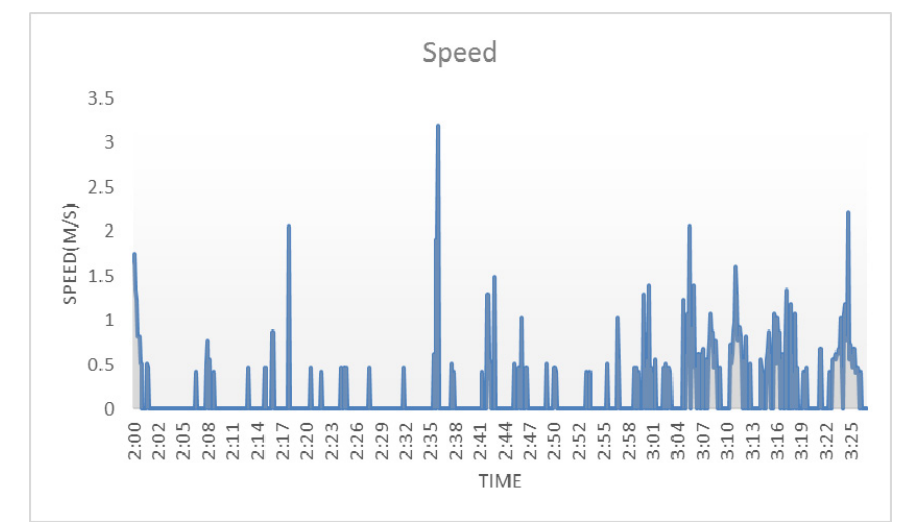

Figure 7. Recorded speed of the WSG during the trial

Table 4.

THE VEHICLE SPEED VS SEA STATE CODE

Comparing this result for forward speed of the WSG robot with the experiment which has been carried out by Smith et al. (2011), the WSG average forward speed has been within the range of sea state 0 (table 4$)$.

Summary of the results of this experiment have been tabulated in table 5 .

\begin{tabular}{|r|r|}
\hline Sea State & Forward Speed $(\mathrm{m} / \mathrm{s})$ \\
\hline Flat Calm & 0 \\
\hline Seas State 0 & 0.13 to 0.26 \\
\hline Sea State 1 & 0.26 to 0.8 \\
\hline Sea State 2 & 0.64 to 1.03 \\
\hline Sea State 3 and above & 0.8 to 1.16 \\
\hline Long Mission Average & 0.8 \\
\hline
\end{tabular}


Salari and Anvar, CFD Modelling and Real-time testing of the Wave Surface Glider (WSG) Robot

Table 5. SUMMARY OF THE RESULTS OF THE TRIAL

The real-time trial of the WSG has exposed the flaws of the existing test-bed. Shortcomings of the forward speed, as well as deflection of the trajectory tracking of the WSG, suggest a number of modifications and adjustments for improvement of the operational efficiency of the WSG in future trials. Next sections have addressed the adjustments and modifications of the current test-bed of the WSG.

\begin{tabular}{|r|r|}
\hline Distance Travelled & $900 \mathrm{~m}$ \\
\hline Duration & 1.5 hours \\
\hline Average Speed & $0.17 \mathrm{~m} / \mathrm{s}$ \\
\hline Maximum speed & $2 \mathrm{~m} / \mathrm{s}$ \\
\hline Sea state & Between 0 and 1 \\
\hline Wave Height & $0.2 \mathrm{~m}$ \\
\hline Depth of water & $22 \mathrm{~m}$ \\
\hline Start Point & $35^{\circ} 0^{\prime} 7.69^{\prime \prime S} 138^{\circ} 20^{\prime} 34.73 " \mathrm{E}$ \\
\hline End Point & $34^{\circ} 59^{\prime} 39.41^{\prime \prime S} 138^{\circ} 20^{\prime} 41.88^{\prime \prime} \mathrm{E}$ \\
\hline
\end{tabular}

\section{PROPOSED MODIFICATIONS FROM LESSONS LEARNED}

Based on the lessons learned from the real-time experimental results, a number of adjustments have been suggested for improvement of the WSG robot performance in real-time. Results from the trial shows that the WSG robot could benefit from extra weight on the submerged part. In addition, changing the location of the connection between the tether and the float could improve maneuverability of the WSG robot in the ocean. Furthermore, width of the wings have been increased in order to make the robot capable of creating more thrust forces.

\section{FUTURE WORK}

Based on the this trial's results, and the modifications suggested and applied to the robot, another trial is recommended for this robot, which could satisfy the requirements of the environmental factors such as higher sea states and hence wave elevation for testing the robot in harsher oceanic conditions.

Furthermore, installation of an inertia sensor, which is capable of measuring the upward and downward acceleration of the float and the glider separately, could be another work that could allow for accessibility to the amount of force the glider generates. Then a comparison can be made between those results and the outcomes obtained from the CFD model presented in this paper.

\section{CONCLUSIONS}

A CFD model has been presented in this paper, which can be taken as a reference model for enhancement of the control and navigation system of this robot in the future.

The results of the successful real-time testing of the robot have been reported and discussed. Suggestions have been made for the improvement of the performance of the robot for real-time applications, which can be referred to as the future work, which can be done on this robot.

\section{ACKNOWLEDGEMENTS}

The authors would like to acknowledge the Defence Science and Technology Group for its support on this research.

\section{REFERENCES}

[1] R. Hine, S. Willcox, G. Hine, and T. Richardson, "The wave glider: A wave-powered autonomous marine vehicle," in OCEANS 2009, MTS/IEEE Biloxi-Marine Technology for Our Future: Global and Local Challenges, 2009, pp. $1-6$.

[2] J. Manley and S. Willcox, "The wave glider: A persistent platform for ocean science," in OCEANS 2010 IEEESydney, 2010, pp. 1-5.

[3] "SHARC SV3 Product Specifications," L. Robotics, Ed., ed, 2013.

[4] N. Kraus and B. Bingham, "Estimation of Wave Glider dynamics for precise positioning," in OCEANS 2011, 2011, pp. 1-9.

[5] B. B. a. B. M. H. Nicholas D. Kraus, "Towards a Dynamic Model of an Autonomous Wave Glider," 2012.

[6] T. Perez, "Ship Motion Control; Course Keeping and Roll Stabilization Using Rudder and Fins," Advances in Industrial Control. Springer, 2005.

[7] S. L. Bales, "Wind and Wave Data for Seakeeping Performance Assessment," Prepared for Seakeeping Comittee ITTC, Athens, Greece, Technical Report1983.

[8] L. H. White and J. L. Hanson, "An automatic sea state calculator," in OCEANS 2000 MTS/IEEE Conference and Exhibition, 2000, pp. 1727-1734.

[9] (2006). Sea State Characteristics. Available: http://www.syqwestinc.com/support/Sea\%20State\%20Table.htm 